\title{
OPTIMAL FREQUENCY SETTING FOR CIRCULAR BUS ROUTES IN URBAN AREAS
}

\author{
Mahmoud Owais ${ }^{1, *}$, Ghada Moussa ${ }^{2}$, Yousef Abbas ${ }^{3}$, Mohamed El-Shabrawy ${ }^{4}$ \\ 1, 2, 3 Civil Engineering Department, Assiut University, Assiut, Egypt \\ ${ }^{4}$ Civil Engineering Department, El-Mansura University, El - Mansura, Egypt
}

Received 4 August 2013; accepted 12 September 2013

\begin{abstract}
This paper is concerned with using a frequency - based passengers' route choice models for circular closed bus routes. Transit passengers, in many cases, deal with overlapping bus routes with some routes sharing common sections and stops. Passenger assignment problem is a major task in frequency setting of bus service which aims to minimize passengers and operator costs. In this work, mixed integer mathematical formulation based on passenger choice problem is developed to track each proportion of passengers' in selecting bus routes for -0- and -1- trips transfer. The proposed model would help for a given transit network and total bus fleet size to minimize network total travel time. It would optimally distribute frequency among bus routes, regarding passengers' interests in selecting bus routes. It differs from traditional models, since it helps in tracking different users while they are moving on the network. Numerical examples are given to clarify the proposed mathematical formulation. Circular bus routes operational performance is tested using Mandl's network benchmark problem. Genetic Algorithm has been implemented with Matlab language in solution procedure. Comparing results with previous work indicates that circular bus routes manage in minimizing average user travel time for the same operator cost. The results from this study would help in further work to optimize transit vehicle size and stops distances along each single bus route.
\end{abstract}

Keywords: Circular bus routes - Frequency setting - Mixed Integer Programming - Genetic Algorithm

\section{Introduction}

With increasing traffic on roads, more mobility-related problems such as congestion, air pollution, noise pollution, and accidents are created. Therefore, the need for new transportation infrastructures for serving new towns and/or improving existing transportation structures to cope with such increase is an urge. These transportation planning, designing and management issues are addressed in the Transit Network Design Problem (TNDP) [1]. The TNDP aims to design a set of bus routes and manage their operation in an efficient manner for both users and operators. Different system functions and targets, required for each group of participants, have to be met through solution methodology. TNDP is simply related to the determination of a set of routes defined over the street network with their corresponding schedules to deal with demand trips [2].

Over the last five decades, the TNDP have been under study for many researchers, most likely because the problem is practically important, theoretically interesting, highly complicated, and multi-disciplinary as well. Solving TNDP depends on solving two subproblems, namely, transit route design problem and frequency setting problem. Transit route design aims to find efficient transit routes that combine maximum demand coverage

* Corresponding author.

Email address: maowais@yahoo.com 
and route network directness. Frequency setting aims to find optimal bus frequency on each transit route which minimizes users and operators costs. Optimization of TNDP solution depends on how

these sub-problems have been tackled $[1,3,4]$.

There are two main approaches to handle TNDP the first approach is to solve the two sub-problems simultaneously taking into account the interaction between them, second approach is to solve route design and frequency settings by separate procedures in a sequential manner $[5,6]$.

Solving TNDP in one stage usually appears as bi-level problem. It stems from the trend to balance between operator's objectives (upper level) and users objectives (lower level). Upper level is normally concerned with route design problem while lower level would concern with frequency setting problem. The model tries to take into account the interaction between supply side and demand side similar to continuous network design problem [7].

To alleviate the complexity of solving TNDP in one stage by bi-level models, some researchers would convert the bi level model to single level by using weighted terms. Operator and users objectives mathematical programming representation are summed and multiplied by weight factors. The value of any weight factor denotes the priority of the term which it multiplied by in the model $[6,8]$.

Chakroborty, 2003, suggests that it is an accepted approximation to take frequency setting phase after route design to alleviate the complexity of TNDP. This trend of solution was accepted by many researches [9, 10, 11, and 12] Owais and Moussa, 2013, presented a deterministic solution methodology for transit route design problem. They developed a Deterministic Route Generation Algorithm (DRGA) for constructing a set of circular closed bus routes in an urban road network [13].

The motivation of this paper is to provide an explicit mathematical programming for transit passenger assignment problem. The model would be able to track the behavior of each proportion of transit passengers in selecting bus routes, for a given set of bus routes defined over transit network and bus available fleet. This would be the key for optimal frequency setting on bus routes. Although, the analysis is mainly concerned with frequency setting on circular route bus route, the proposed model can be easily extended to other type of bus routes.

\section{Passenger Assignment on Circular Bus Routes}

In the operation side of the TNDP (bus service frequency setting problem), the planner is interested in setting bus frequency on the network in the most precise way regarding which routes to be used and loaded, according to passengers' interest. The problem arisen here is transit passenger assignment problem. It is the major component in transit route frequency setting. It can be defined as the query of passenger flows on transit networks segments. Passenger assignment is a process of predicting passengers' behavior in selecting bus routes according to route time length and bus frequency for each bus route [14].

Transit passengers in many cases have to deal with overlapping bus route with some routes sharing sections and common stops. This problem is sub-problem of transit passenger assignment, called common-lines problem. Various assumptions and studies are made in order to track passengers' behavior towards a given supply of transit service $[15,16]$.

Journal of Engineering Sciences, Assiut University, Faculty of Engineering, Vol. 41, No. 5, September, 2013,E-mail address: jes@aun.edu.eg 
Spiess, 1983, developed the concept of clever passenger into passenger optimal strategies. Passengers would minimize the sum of waiting time and in-vehicle time in their boarding strategies. If there is more than one route serving an origin node (i) and destination node (j), see Fig. (1). This would lead the passengers, who wish to travel from (i) to (j), to determine a sub-set of bus routes (attractive lines) boarding the first incoming bus of these routes. The fraction of passengers $\left(\mathrm{P}_{\mathrm{r}}\right)$ served by each route $\mathrm{r} \in R^{a}$, considering $R^{a}$ is the set of attractive lines between (i) and (j), would be estimated as;

$\mathrm{P}_{\mathrm{r}}=\frac{\mathrm{f}_{\mathrm{r}}}{\sum_{\mathrm{r} \in R} a \mathrm{f}_{\mathrm{r}}}$

The expected waiting (E[WT])time is given as;

$\mathrm{E}[\mathrm{WT}]=\frac{\alpha}{\sum_{r \in R^{a}} f_{r}}$

where; $\alpha$ is a parameter, such that $\alpha=1$ for Poisson vehicle arrivals (as adopted in this research), or $\alpha=0.5$ for deterministic arrivals, $f_{r}=$ frequency of route $r$. Attractive lines set depends on routes travel time and frequency.

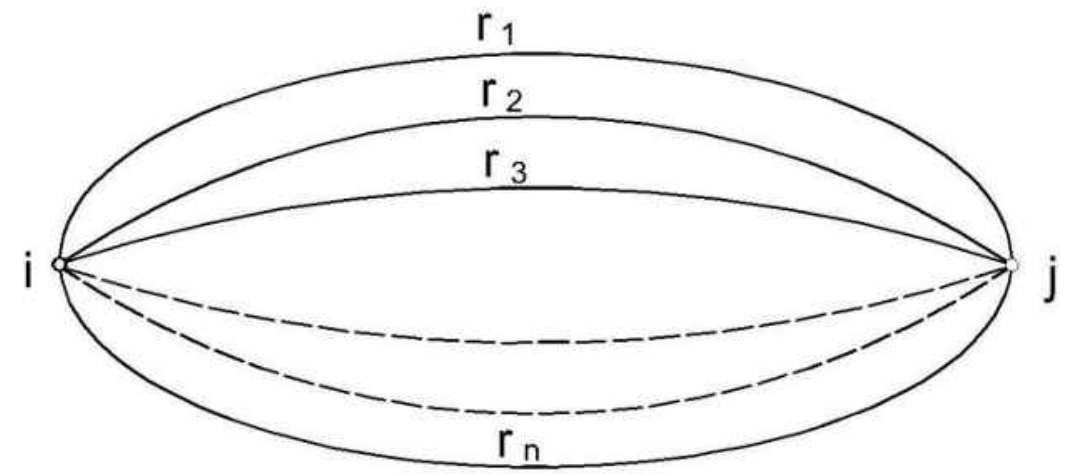

Fig. 1. $i-j$ set of routes (arcs)

For origin node (i) the relaxation of the problem can be defined as [14, 17 and 18];

$\operatorname{minimize} \sum_{a \in A} t_{a} v_{a}+\sum_{i \in N} \omega_{i}$

s.t.

$$
\begin{array}{lc}
\sum_{\mathrm{a} \in \mathrm{A}_{\mathrm{i}}^{+}} \mathrm{v}_{\mathrm{a}}-\sum_{\mathrm{a} \in \mathrm{A}_{\mathrm{i}}^{-}} \mathrm{v}_{\mathrm{a}}=\mathrm{bi} & \forall \mathrm{i} \in \mathrm{N} \\
\omega_{\mathrm{i}}=\frac{\mathrm{D}_{\mathrm{i}}}{\sum_{\mathrm{a} \in \mathrm{A}_{\mathrm{i}}^{+}}^{+} \mathrm{f}_{\mathrm{a}} \mathrm{x}_{\mathrm{a}}} & \forall \mathrm{i} \in \mathrm{N} \\
\mathrm{v}_{\mathrm{a}} \leq \mathrm{f}_{\mathrm{a}} \omega_{\mathrm{i}} & \forall \mathrm{a} \in \mathrm{A}_{\mathrm{i}}^{+}, \forall \mathrm{i} \in \mathrm{N} \\
\mathrm{v}_{\mathrm{a}} \geq 0 & \forall \mathrm{a} \in \mathrm{A}_{\mathrm{i}}
\end{array}
$$

In this paper we propose mixed integer formulation which would track each portion of passengers' behavior in selecting bus routes from origin (i) to destination (j) and passing through transfer node (m), if it is existed. Also, we would symbolize the number of trips travelling from (i) to $(\mathrm{j})$ using route $\mathrm{r}$ with $\mathrm{g}_{\mathrm{i}-\mathrm{j}}^{\mathrm{r}}$ which is considered our main decision

Journal of Engineering Sciences, Assiut University, Faculty of Engineering, Vol. 41, No. 5, September, 2013,E-mail address: jes@aun.edu.eg 
variable in determining optimal bus frequency distribution among bus routes for a certain total bus fleet. In this work, we would assume that;

- Passenger would select bus route, among subset of bus routes, that minimizes total trip travel time (in -vehicle plus waiting time), boarding the first incoming bus from this subset.

- Passenger wouldn't transfer if there is a direct route to his/ her destination; even if the transfer would minimize the total trip travel time.

- Passenger, who would transfer, predetermines a certain transfer node which is the closet possible transfer node to his destination node.

- Arriving bus capacity is enough for waiting passengers.

\subsection{Single circular bus route analysis (trips without transfer)}

Interestingly, the single circular bus route itself includes common-lines problem. Circular bus route is a bus route which starts at a certain node and traverses other nodes once, then terminates at the start node. This type of routes includes two loops; clockwise and anticlockwise directions (i.e. each single circular route constitutes two different routes). At a certain origin node, each one of the two directions can serve passengers to all other destination nodes on the circular route, but mostly, one of the two directions is short and the other is long (according to in-vehicle time) to destination node, as depicted in Fig (2).

Considering a number of passengers $\left(\mathrm{d}_{\mathrm{i}-\mathrm{j}}\right)$ that would move from (i) to $(\mathrm{j})$, they would choose between the two paths $\left(r_{1} \& r_{2}\right)$, since $t_{i-j}^{r 1}$ and $t_{i-j}^{r 2}$ are the travel time on $r_{1}$ (the short direction) and $r_{2}$ (the long direction), see Fig. (2). If all passengers are willing to take the shortest route $\left(r_{1}\right)$, it would cause each passenger to expertise total travel time (invehicle plus waiting time) equal to; $t_{i-j}^{r 1}+1 /\left(f r_{1}\right)$.

Passengers try to minimize their total travel time by boarding the first incoming bus of the two routes, if only; $\left[t_{i-j}^{r 2}+1 /\left(f r_{1}+f r_{2}\right)\right] \leq t_{i-j}^{r 1}+1 /\left(f r_{1}\right)$. It would be attractive to passengers to choose between the two paths. Total trips $\left(\mathrm{d}_{\mathrm{i}-\mathrm{j}}\right)$ would split into $g_{i-j}^{r 1} \& g_{i-j}^{r 2}$ according to $f r_{1} \& f r_{2}$.

$$
\begin{aligned}
& g_{i-j}^{r 1}=\mathrm{d}_{\mathrm{i}-\mathrm{j}} \times f r_{1} /\left(f r_{1}+f r_{2}\right) \\
& g_{i-j}^{r 2}=\mathrm{d}_{\mathrm{i}-\mathrm{j}} \times f r_{2} /\left(f r_{1}+f r_{2}\right)
\end{aligned}
$$

Total travel time for all users $=\left[t_{i-j}^{r 1}+1 /\left(f r_{1}+f r_{2}\right)\right] \times g_{i-j}^{r 1}+\left[t_{i-j}^{r 2}+1 /\left(f r_{1}+f r_{2}\right)\right] \times g_{i-j}^{r 2}$

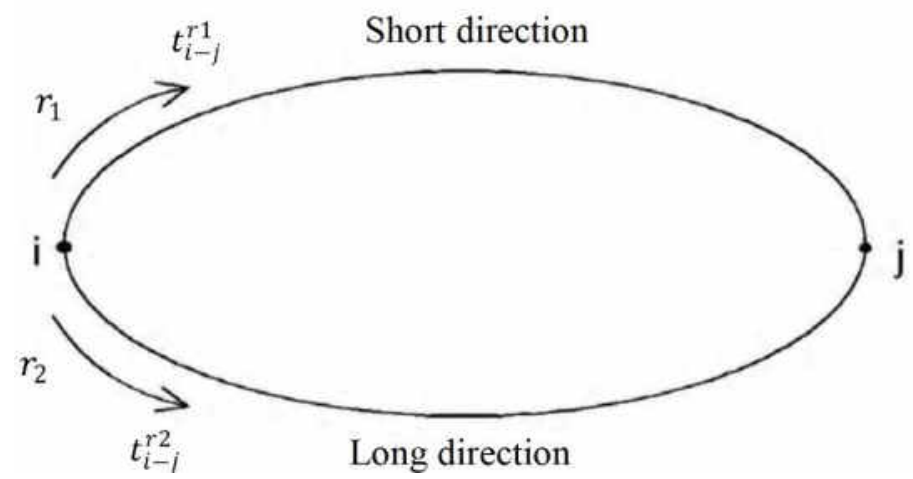

Fig. 2. circular route configuration

Journal of Engineering Sciences, Assiut University, Faculty of Engineering, Vol. 41, No. 5, September, 2013,E-mail address: jes@aun.edu.eg 
To track passengers behavior in selecting bus routes (each number of passengers uses route $\mathrm{r}, g_{i-j}^{r}$ ), we would represent the problem solution by mixed integer programming. The travel time for user would be given as optimization problem minimize $\sum_{r \in R_{i}^{j}} t_{i-j}^{r} \times \delta_{i-j}^{r}$ (in -vehicle time) $+\frac{1}{\sum_{r \in R_{i}^{j}} f_{r} \times \delta_{i-j}^{r}}$ (waiting time)

It would be written as;

Minimize $\frac{1+\sum_{r \in R_{i}^{j}} f_{r} \times t_{i-j \times \delta_{i-j}^{r}}^{r}}{\sum_{r \in R_{i}^{j}} f_{r} \times \delta_{i-j}^{r}}$

For all users, it would be written as;

$\operatorname{Minimize} \sum_{r \in R_{i}^{j}} g_{i-j}^{r} \times \frac{1+\sum_{r \in R_{i}^{j}} f_{r} \times t_{i-j \times \delta_{i-j}^{r}}^{r}}{\sum_{r \in R_{i}^{j}} f_{r} \times \delta_{i-j}^{r}}$

s.t.

$\begin{array}{ll}g_{i-j}^{r}=\mathrm{d}_{\mathrm{i}-\mathrm{j}} \times \frac{f_{r} \times \delta_{i-j}^{r}}{\sum_{r \in R_{i}^{j}} f_{r} \times \delta_{i-j}^{r}} & \forall r \\ \sum_{r} g_{i-j}^{r} \times \delta_{i-j}^{r}=\mathrm{d}_{\mathrm{i}-\mathrm{j}} & \end{array}$

A simple numerical example is given to clarify passengers' decisions for selecting bus routes according to a certain circular route configuration (see Fig. (2)) and three cases of bus service;

\section{Example Cases:}

Case (1)

Given $\mathrm{d}_{\mathrm{i}-\mathrm{j}}=100 \mathrm{trip} / \mathrm{hr}, t_{i-j}^{r 1}=9 \mathrm{~min}, t_{i-j}^{r 2}=11 \mathrm{~min}$ (total circular route length $=20 \mathrm{~min}$ ), $f_{r 1}=12 \mathrm{bus} / \mathrm{hr}, f_{r 2}=12 \mathrm{bus} / \mathrm{hr}$ (total fleet size $=8$ ).

$$
\text { minimize } g_{i-j}^{r 1} \times \frac{1+9 \times \frac{12}{60} \times \delta_{i-j}^{r 1}+11 \times \frac{12}{60} \times \delta_{i-j}^{r 2}}{\frac{12}{60} \times \delta_{i-j}^{r 1}+\frac{12}{60} \times \delta_{i-j}^{r 2}}+g_{i-j}^{r 2} \times \frac{1+9 \times \frac{12}{60} \times \delta_{i-j}^{r 1}+11 \times \frac{12}{60} \times \delta_{i-j}^{r 2}}{\frac{12}{60} \times \delta_{i-j}^{r 1}+\frac{12}{60} \times \delta_{i-j}^{r 2}}
$$

s.t

$$
\begin{aligned}
& g_{i-j}^{r 1}=100 \times \frac{12 \times \delta_{i-j}^{r 1}}{12 \times \delta_{i-j}^{r 1}+12 \times \delta_{i-j}^{r 2}} \\
& g_{i-j}^{r 2}=100 \times \frac{12 \times \delta_{i-j}^{r 2}}{12 \times \delta_{i-j}^{r 1}+12 \times \delta_{i-j}^{r 2}} \\
& g_{i-j}^{r 1} \times \delta_{i-j}^{r 1}+g_{i-j}^{r 2} \times \delta_{i-j}^{r 2}=100
\end{aligned}
$$

Solution:

$\delta_{i-j}^{r 1}=1$

$g_{i-j}^{r 1}=50$ trips

$\delta_{i-j}^{r 2}=1$

Total travel time $=1250 \mathrm{~min}$

$g_{i-j}^{r 2}=50$ trips

Average travel time $($ ATT $)=12.5 \mathrm{~min} /$ user

Journal of Engineering Sciences, Assiut University, Faculty of Engineering, Vol. 41, No. 5, September, 2013, E-mail address: jes@aun.edu.eg 


\section{Case (2):}

Given $\mathrm{d}_{\mathrm{i}-\mathrm{j}}=100 \mathrm{trip} / \mathrm{hr}, t_{i-j}^{r 1}=9 \mathrm{~min}, t_{i-j}^{r 2}=11 \mathrm{~min}, f_{r 1}=18 \mathrm{bus} / \mathrm{hr}, f_{r 2}=6 \mathrm{bus} / \mathrm{hr}$, (total bus fleet $=8$ )

$$
\text { minimize } g_{i-j}^{r 1} \times \frac{1+9 \times \frac{18}{60} \times \delta_{i-j}^{r 1}+11 \times \frac{9}{60} \times \delta_{i-j}^{r 2}}{\frac{18}{60} \times \delta_{i-j}^{r 1}+\frac{6}{60} \times \delta_{i-j}^{r 2}}+g_{i-j}^{r 2} \times \frac{1+9 \times \frac{18}{60} \times \delta_{i-j}^{r 1}+11 \times \frac{6}{60} \times \delta_{i-j}^{r 2}}{\frac{18}{60} \times \delta_{i-j}^{r 1}+\frac{6}{60} \times \delta_{i-j}^{r 2}}
$$

s.t

$$
\begin{aligned}
& g_{i-j}^{r 1}=100 \times \frac{18 \times \delta_{i-j}^{r 1}}{18 \times \delta_{i-j}^{r 1}+6 \times \delta_{i-j}^{r 2}} \\
& g_{i-j}^{r 2}=100 \times \frac{6 \times \delta_{i-j}^{r 2}}{18 \times \delta_{i-j}^{r 1}+6 \times \delta_{i-j}^{r 2}} \\
& g_{i-j}^{r 1} \times \delta_{i-j}^{r 1}+g_{i-j}^{r 2} \times \delta_{i-j}^{r 2}=100
\end{aligned}
$$

Solution:
$\delta_{i-j}^{r 1}=1$
$\delta_{i-j}^{r 2}=0$
$g_{i-j}^{r 1}=100$ trips
$g_{i-j}^{r 2}=0$
Total travel time $=1233.34 \mathrm{~min}$
$\mathrm{ATT}=12.34 \mathrm{~min} / \mathrm{user}$

\section{Case (3)}

Given $\mathrm{d}_{\mathrm{i}-\mathrm{j}}=100 \mathrm{trip} / \mathrm{hr}, t_{i-j}^{r 1}=9 \mathrm{~min}, t_{i-j}^{r 2}=11 \mathrm{~min}, f_{r 1}=$ ? bus $/ \mathrm{hr}, f_{r 2}=$ ? bus $/ \mathrm{hr}$, and total bus fleet $=8$

minimize $g_{i-j}^{r 1} \times \frac{1+9 \times f_{r 1} \times \delta_{i-j}^{r 1}+11 \times f_{r 2} \times \delta_{i-j}^{r 2}}{f_{r 1} \times \delta_{i-j}^{r 1}+f_{r 2} \times \delta_{i-j}^{r 2}}+g_{i-j}^{r 2} \times \frac{1+9 \times f_{r 1} \times \delta_{i-j}^{r 1}+11 \times f_{r 2} \times \delta_{i-j}^{r 2}}{f_{r 1} \times \delta_{i-j}^{r 1}+f_{r 2} \times \delta_{i-j}^{r 2}}$

s.t.

$$
\begin{aligned}
& g_{i-j}^{r 1}=100 \times \frac{f r_{1} \times \delta_{i-j}^{r 1}}{f r_{1} \times \delta_{i-j}^{r 1}+f r_{2} \times \delta_{i-j}^{r 2}} \\
& g_{i-j}^{r 2}=100 \times \frac{f r_{1} \times \delta_{i-j}^{r 2}}{f r_{1} \times \delta_{i-j}^{r 1}+f r_{2} \times \delta_{i-j}^{r 2}} \\
& g_{i-j}^{r 1} \times \delta_{i-j}^{r 1}+g_{i-j}^{r 2} \times \delta_{i-j}^{r 2}=100 \\
& f r_{1} \times \frac{20}{60} \times \delta_{i-j}^{r 1}+f r_{2} \times \frac{22}{60} \times \delta_{i-j}^{r 2}=8
\end{aligned}
$$

Solution:

$\delta_{i-j}^{r 1}=1$

$\delta_{i-j}^{r 2}=0$

$g_{i-j}^{r 1}=100$ trips

$g_{i-j}^{r 2}=0$

$f r_{1}=24 \mathrm{bus} / \mathrm{hr}$

$f r_{2}=0$

Total travel time $=1150 \mathrm{~min}$

$\mathrm{ATT}=11.5 \mathrm{~min} / \mathrm{user}$

Journal of Engineering Sciences, Assiut University, Faculty of Engineering, Vol. 41, No. 5, September, 2013,E-mail address: jes@aun.edu.eg 
Remarks on the given example

In cases (1 and 2), it was obvious that passenger's route choice depending mainly on routes' frequency. Therefore, in case (3) the question arises, what are the best frequencies (for the same total bus fleet 8 bus) on route 1 and route 2 , which would minimize total passengers' travel time? The model reaches equilibrium, when there is no change on $f r_{1}$ or $f r_{2}$, and would minimize passengers' total travel time.

The proposed model for bus route frequency setting, would minimize total travel time for all transit network users, for a given transit network (set of circular routes) and total bus fleet size (budget constraint). This would be achieved by optimally disturbing frequency among bus routes, taking into account passengers' interests in selecting bus routes.

\subsection{Multi-common circular bus routes analysis (trips with transfer)}

Transit network constitutes mainly two types of trips; -0- transfer trips and -1- transfer trips. The analysis of - 0 - transfer trips would be considered as in Section 2.1 (i.e. origin and destination served by common routes). Trips with -1 - transfer are more complicated in their analysis, since passengers are travelling using transfer node and two different routes. Trips with -2- transfer can be tracked as -1- transfer trips, in which -2- transfer trips include two transfer nodes and three routes selecting decisions. Since -2- transfer trips are usually a negligible proportion in transit networks, they were excluded from the analysis.

Passenger, with no direct route to his/ her destination, would choose among attractive routes at the origin node to a certain transfer node. This would be repeated at the transfer node to the destination node. Passenger's decision depends on routes travel time and frequencies for both origin and transfer nodes.

To better understand -1- transfer trips analysis on circular routes, a small transit network, Fig. (3), consists of two circular routes with node sequence (i-m-l-i \& k-m-l-k) with common link (ml). It includes an origin node (i) with destination node (k).

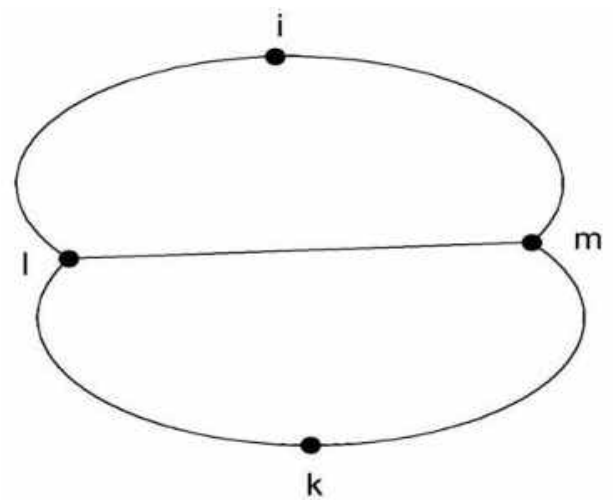

Fig. 3. Small transit network

If a certain passenger would travel form $\mathrm{i}$ to $\mathrm{k}$, he would first choose his attractive transfer point ( $\mathrm{m}$ or $\mathrm{l}$ ). If he considers $(\mathrm{m})$ as the attractive transfer point for (i-k) trips, he would select first route (sr) to $(\mathrm{m})$ transfer node and then second route (er) to (k) destination node. Different available scenarios for passenger's decisions for travelling from (i) to (k) can be adopted, see Fig. (4).

Journal of Engineering Sciences, Assiut University, Faculty of Engineering, Vol. 41, No. 5, September, 2013,E-mail address: jes@aun.edu.eg 


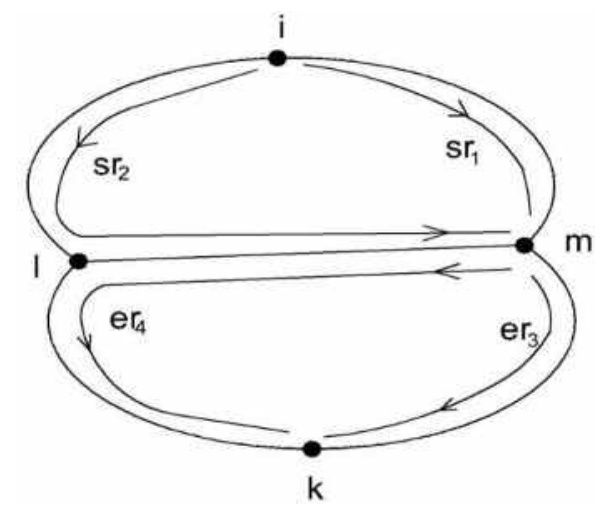

Fig. 4. Different scenarios for $i-k$ trips using $(m)$ as transfer point

In passenger's decision for traveling from i to k using node $(\mathrm{m})$, as attractive transfer point, one of the set of attractive routes at node (i) and at node (m) would be selected. The passenger decision would be as an optimization process;

$\operatorname{minimize} \frac{1+\sum_{s r} f_{s r} \times t_{i-m}^{s r} \times \delta_{i-m}^{s r}}{\sum_{s r} f_{s r} \times \delta_{i-m}^{s}}($ decision at i $)+\frac{1+\sum_{e r} f_{e r} \times t_{m-k}^{e r} \times \delta_{m-k}^{e r}}{\sum_{e r} f_{e r} \times \delta_{m-k}^{e r}}($ decision at m)

For all users;

minimize $\sum_{s r} g_{i-m}^{s r} \times \frac{1+\sum_{s r} f_{s r} \times t_{i-m}^{s r} \times \delta_{i-m}^{s r}}{\sum_{s r} f_{s r} \times \delta_{i-m}^{s}}+\sum_{e r} g_{m-k}^{e r} \times \frac{1+\sum_{e r} f_{e r} \times t_{m-k}^{e r} \times \delta_{m-k}^{e r}}{\sum_{e r} f_{e r} \times \delta_{m-k}^{e r}}$

s.t.

$g_{i-m}^{s r}=\mathrm{d}_{\mathrm{i}-\mathrm{k}} \times \frac{f_{s r} \times \delta_{i-m}^{s r}}{\sum_{s r} f_{r} \times \delta_{i-m}^{s r}} \quad \forall s r$

$g_{m-k}^{e r}=\mathrm{d}_{\mathrm{i}-\mathrm{k}} \times \frac{f_{e r} \times \delta_{m-k}^{e r}}{\sum_{e r} f_{e r} \times \delta_{m-k}^{e r}} \quad \forall e r$

$\sum_{s r} g_{i-j}^{s r} \times \delta_{i-j}^{s r}=\sum_{e r} g_{i-j}^{e r} \times \delta_{i-j}^{e r}=\mathrm{d}_{\mathrm{i}-\mathrm{k}}$

\subsection{General mathematical optimization model for passenger assignment problem}

To derive a general mathematical optimization model for frequency setting on transit route network, we would assume; $\forall \mathrm{i} \in \mathrm{N}$ there are two groups of destination nodes ( 1 and k). 1 represents set of nodes satisfied directly (without transfer) by bus routes and $\mathrm{k}$ represents set of nodes satisfied with one transfer. $m$ represents the attractive transfer node for $\mathrm{i}-\mathrm{j}$ trips, once $\mathrm{j} \in k$.

$\operatorname{minimize} \sum_{i \in N} \sum_{j \in l} \sum_{r \in R_{i}^{j}} g_{i-j}^{r} \times \frac{1+\sum_{r \in R_{i}^{j}} f_{r} \times t_{i-j}^{r} \times \delta_{i-j}^{r}}{\sum_{r \in R_{i}^{j}} f_{r} \times \delta_{i-j}^{r}}+\sum_{i \in N} \sum_{j \in k} \sum_{r \in s r} g_{i-m}^{r} \times$
$\frac{1+\sum_{r \in s r} f_{r} \times t_{i-m}^{r} \times \delta_{i-m}^{r}}{\sum_{r \in s r} f_{r} \times \delta_{i-m}^{r}}+\sum_{i \in N} \sum_{j \in k} \sum_{r \in e r} g_{m-j}^{r} \times \frac{1+\sum_{r \in e r} f_{r} \times t_{m-j}^{r} \times \delta_{m-j}^{r}}{\sum_{r \in e r} f_{r} \times \delta_{m-j}^{r}}$ s.t.

$$
g_{i-j}^{r}=\mathrm{d}_{\mathrm{i}-\mathrm{j}} \times \frac{f_{r} \times \delta_{i-j}^{r}}{\sum_{r \in R_{i}^{j}} f_{r} \times \delta_{i-j}^{r}} \quad \forall r \in R_{i}^{j}, \mathrm{i} \in N, \mathrm{j} \in l
$$

Journal of Engineering Sciences, Assiut University, Faculty of Engineering, Vol. 41, No. 5, September, 2013,E-mail address: jes@aun.edu.eg 


$$
\begin{array}{ll}
g_{i-m}^{r}=\mathrm{d}_{\mathrm{i}-\mathrm{j}} \times \frac{f_{r} \times \delta_{i-m}^{r}}{\sum_{r \in s r} f_{r} \times \delta_{i-m}^{r}} & \forall r \in s r, \mathrm{i} \in N, \mathrm{j} \in k \\
g_{m-j}^{r}=\mathrm{d}_{\mathrm{i}-\mathrm{j}} \times \frac{f_{r} \times \delta_{m-j}^{r}}{\sum_{r \in e r} f_{r} \times \delta_{m-j}^{r}} & \forall r \in e r, \mathrm{j} \in k \\
\sum_{r} g_{i-j}^{r} \times \delta_{i-j}^{r}=\mathrm{d}_{\mathrm{i}-\mathrm{j}} & \forall r \in R_{i}^{j}, \mathrm{i} \in N, \mathrm{j} \in l \\
\sum_{r} g_{i-m}^{r} \times \delta_{i-m}^{r}=\mathrm{d}_{\mathrm{i}-\mathrm{j}} & \forall r \in s r, \mathrm{i} \in N, \mathrm{j} \in k \\
\sum_{r} g_{m-j}^{r} \times \delta_{m-j}^{r}=\mathrm{d}_{\mathrm{i}-\mathrm{j}} & \forall r \in e r, \mathrm{j} \in k \\
f_{\min } \leq f_{r} \leq f_{m a x} & \forall r \in R \\
\sum_{r \in R} f_{\mathrm{r}} \times \mathrm{T}_{\mathrm{r}} \leq \mathrm{TBF} & \forall i \in N, \mathrm{r} \in \mathrm{R} \\
f_{r} \times \mathrm{V}_{\mathrm{s}} \leq \sum_{j} g_{i-j}^{r} &
\end{array}
$$

\section{Solution Search Tool}

The proposed model at Equation (18) is a mixed integer nonlinear model, since it includes continuous variables $g_{i-j}^{r}$ and $f_{r}$ besides integer variable $\delta_{i-j}^{r}$. Nonlinearity of the model is back to flow splitting constraints Eq. $(19-21)$. The proposed model is difficult to be solved by exact methods, so we would propose Genetic Algorithm as stochastic search tool for solving the proposed model.

Genetic Algorithm (GA) is a powerful stochastic search tool, which is used in solving many mathematical programming problems by examining a large part of search space aiming to find optimal or near optimal solution. GA depends on the theory of evolution of genetics that next generation would be better than parents. Representing random population of individuals (feasible solution) as binary code (chromosomes) is considered the first generation for GA. Three sequential operators deal with this Generation to produce the next one (sons is better than parents), these operators namely, selection, reproduction and mutation. The reproduced generation is considered an initial solution for the next generation. The process continues until defined criteria of convergence are met, for more details see [19].

GA is one of the most preferable tools for solving Transit Network Design Problem. Usually, when one tackles TNDP solution as one part or partitions it into sub-problems. Different types of mathematical optimization models arise in solution procedure, such as; mixed integer programming, combinatorial integer programming and non-linear nonconvex programming. These types are difficult (or impossible) to be solved with exact methods. GA is considered a plausible tool to tackle these problems to reach optimal or near optimal solution $[2,4]$.

Matlab 2011 provides an easy graphical user inter face (GUI) to deal with Genetic Algorithm. Genetic Algorithm GUI eases changing its operator's criteria or conditions of convergence for GA like number of maximum generations, maximum running time limit and etc. This would result in improving GA final results [20].

Journal of Engineering Sciences, Assiut University, Faculty of Engineering, Vol. 41, No. 5, September, 2013,E-mail address: jes@aun.edu.eg 
Mahmoud Owais et al.,Optimal frequency setting for Circular bus routes in urban area, pp. 1796 - 1811

\section{Illustrative Numerical Example for TNDP Solution using DRGA and GA}

\subsection{Mandl's Benchmark transit network}

In order to demonstrate the effectiveness of the solution methodology proposed in this paper, a popular benchmark network is solved (Mandl's Swiss transit network). Mandl's Swiss transit network is the most popular transit network that has been utilized by many researchers as a benchmark network to compare their results with Mandl's solution results [2, 9, 10, 21 and 22]. Mandl's transit network consists of 15 nodes connected by 21 links with a total demand of 15570 trips; see Fig. 5 [9].

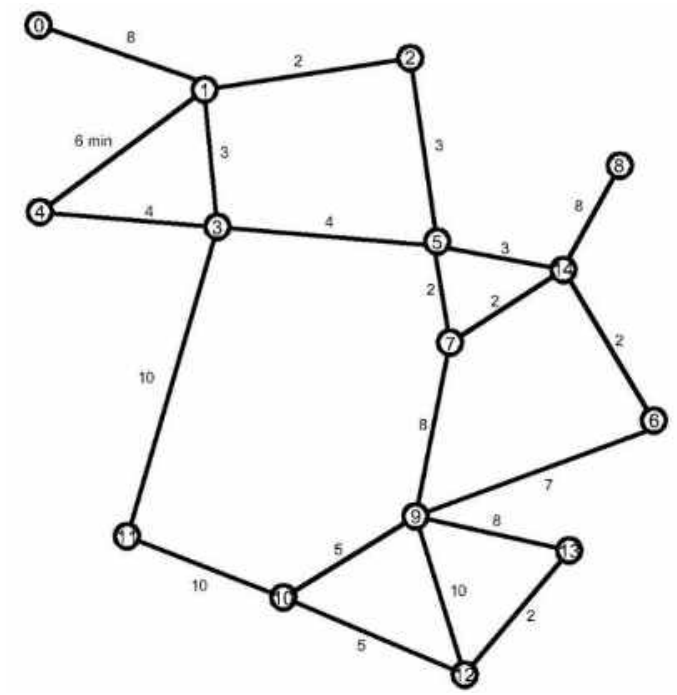

Fig. 5. Mandl's Network with travel time on links in minutes, reproduced from Mandl, 1980 [9]

\subsection{Solution procedure for Mandl's transit network}

Our adopted approach to solve the TNDP follows two consecutive stages; 1). Solve transit route design problem, 2). Solve frequency setting problem. In the first stage, the DRGA, as a deterministic approach produced by Owais and Moussa, 2013, is used to generate a set of circular bus routes for Mandl's network. The output from the first stage is used as an input for the second stage. In the second stage, the frequency setting on the set of circular bus routes is analyzed via GA, as a stochastic search tool, to solve the general mixed integer nonlinear model for Mandl's network. The frequency setting stage aims to minimize total travel time for all transit network users (user cost) by optimally disturbing frequency among bus routes, taking into account passengers' interests in selecting bus routes for a given operator budget (total bus fleet constraint).

The proposed solution assumes that the minimum and the maximum bus frequency on each bus route are 6 and $30 \mathrm{bus} / \mathrm{hr}$, respectively. Bus vehicle capacity is fixed at 40 seats per bus. Transfer penalty is calculated by assuming five minutes as penalty for each trip doesn't have a direct route to its destination. In the next section, the DRGA and GA

Journal of Engineering Sciences, Assiut University, Faculty of Engineering, Vol. 41, No. 5, September, 2013,E-mail address: jes@aun.edu.eg 
solution results are presented and compared with some other approaches in terms of some planning and operational parameters.

The planning parameters include; number of routes, total route length (in min), percentage of demand coverage (with zero-, one-, and two- transfers), route network directness, and the transfer directness. Route network directness is an indicator to measure bus route deviation from the shortest path among main transit nodes pairs. In which, the value of route network directness which equals one indicates that all bus users would take the shortest path along their travel between origin and destination. The value of route network directness which exceeds one would indicate the delay caused by the set of bus routes to all users. The transfer directness is calculated as route network directness but for transfer trips only.

The operational parameters include; total demand served by the set of bus routes divided by total bus fleet size "TBF" (main operator cost), average in vehicle time (in min per user), average waiting time (in min per user), total transfer penalty (in min), average total travel time "ATT" (in min per user), and finally the DRGA and GA percentage of saving in average user travel time over other approaches.

\subsection{Results and discussions}

The first stage, using DRGA, resulted in four circular bus routes, see Fig 6. It is worth noting that the DRGA algorithm searches only for circular closed bus routes (DRGA doesn't work with nodes connected by only one link), therefore, nodes $(0,8)$ were excluded from the analysis. The resulted network consists of 13 nodes with a total demand of 12370 trips per day.

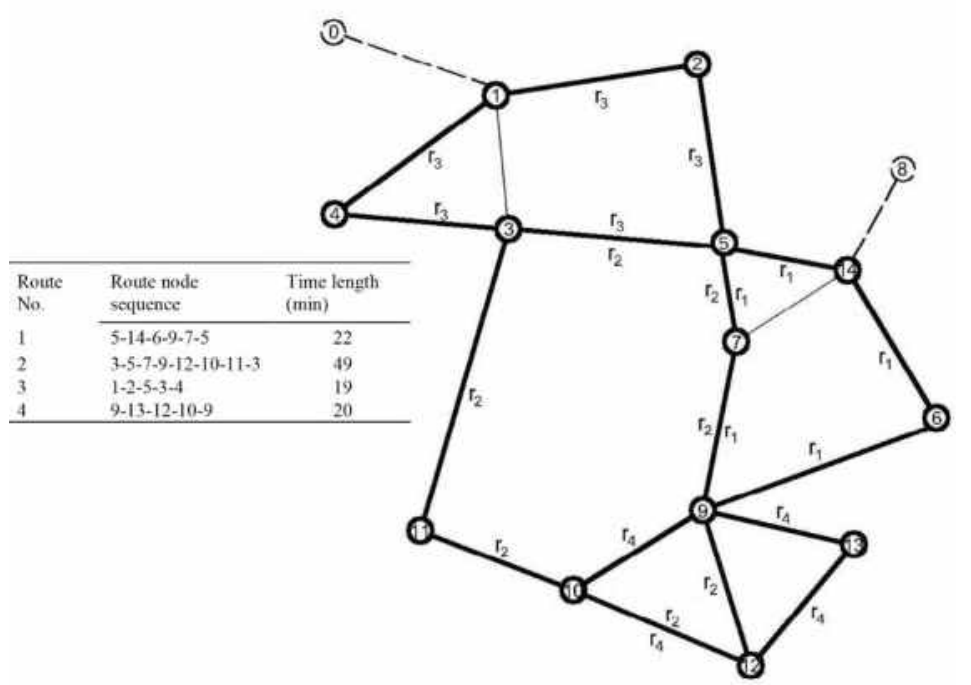

Fig. 6. DRGA set of routes configuration for Mandl's network

The results from DRGA and GA analysis are presented in Table (2) along with those from previous work. The first row indicates the source of the solutions to the benchmark problem. The second row gives the previous work year. The third row identifies the solutions search tool methods to the problem. Fourth to tenth row denote the route network

Journal of Engineering Sciences, Assiut University, Faculty of Engineering, Vol. 41, No. 5, September, 2013,E-mail address: jes@aun.edu.eg 
characteristics (planning parameters). The remaining rows give the operational parameters for transit network solutions.

The proposed set of circular bus routes has advantage over other bus routes, under comparison, in mobility technique. In which, all other bus routes under comparison are shuttle bus service routes (i.e. bus moves forward and backward on the same line), but proposed bus routes are circular (i.e. bus moves on circular closed line). This technique allows single bus route to collect more nodes (more demand coverage) while keeping route directness.

The number of routes generated is considered, in regard with other planning parameters under comparison, the most important criteria in judging the planning efficiency of the solution. Less number of routes demonstrates the methodology strength in assembling candidate links in one continuous bus route and entails - accordingly - less number of common lines, which reduces the computational effort of frequency setting part. The DRGA solution has a set of four circular routes with total route length $=110 \mathrm{~min}$ to achieve demand coverage $\left(D_{0}=84.41 \%, D_{01}=15.43 \%, D_{02}=0.16\right)$, however S\&M, 1994, for example- constructed eight routes with route length $=151 \mathrm{~min}$ to achieve demand coverage $\left(D_{0}=87.73 \%, D_{01}=12.27\right)$. Bagloee and Ceder, 2011, (recent research) implemented intense mathematical programming representation equipped with two search heuristic algorithms (Genetic Algorithm and Ant System) to produce twelve bus routes covering $83.66 \%$ directly with total route length of $261 \mathrm{~min}$. Moreover, DRGA solution increases the transit attractiveness through keeping the best value of network directness considering total network directness along with transfer directness. It has the minimum value of transfer directness (1.06), so it would encourage even indirect origin destination trips to take the transit service.

DRGA and GA solution, at the same main operator cost, the total demand served by the set of routes divided by total bus fleet size "TBF", the proposed circular bus routes could save in the average user travel time (user cost) compared with other pervious works' solutions. Compared with Mandl's, pioneer work, DRGA set of routes could save up to nearly 20 percent of average total travel time. Compared with Blgoee \& Ceder, recent work could save up to 10 percent. DRGA and GA could improve the solution of TNDP in terms of planning parameters along with operational parameters.

\section{Table 2.}

Comparison with Pervious Works Approaches for Mandl’s Benchmark Transit network

\begin{tabular}{|c|c|c|c|c|c|c|c|c|}
\hline Problem source & \multicolumn{2}{|c|}{ Mandl [9] } & \multicolumn{2}{|c|}{$\begin{array}{c}\text { Baaj and } \\
\text { Mahmassani [10] }\end{array}$} & \multicolumn{2}{|c|}{$\begin{array}{c}\text { Shih and } \\
\text { Mahmassani [21] }\end{array}$} & \multicolumn{2}{|c|}{$\begin{array}{c}\text { Bagloee \&Ceder } \\
{[23]}\end{array}$} \\
\hline Year & \multicolumn{2}{|c|}{1980} & \multicolumn{2}{|c|}{1991} & \multicolumn{2}{|c|}{1994} & \multicolumn{2}{|c|}{2011} \\
\hline Search method & Mandl $^{1}$ & $\begin{array}{l}\text { DRGA } \\
\& \text { GA }\end{array}$ & $\mathrm{B} \& \mathrm{M}^{2}$ & $\begin{array}{l}\text { DRGA } \\
\& \text { GA }\end{array}$ & $S \& M^{3}$ & $\begin{array}{l}\text { DRGA } \\
\text { \& GA }\end{array}$ & $\begin{array}{l}\text { GI\& } \\
\mathrm{AS}^{4}\end{array}$ & $\begin{array}{l}\text { DRGA } \\
\& \text { GA }\end{array}$ \\
\hline Number of routes & 4 & 4 & 7 & 4 & 8 & 4 & 12 & 4 \\
\hline-0 - transfer trips $\%$ & 69.94 & 84.41 & 80.99 & 84.41 & 82.59 & 84.41 & 83.66 & 84.41 \\
\hline
\end{tabular}

Journal of Engineering Sciences, Assiut University, Faculty of Engineering, Vol. 41, No. 5, September, 2013,E-mail address: jes@aun.edu.eg 
Mahmoud Owais et al.,Optimal frequency setting for Circular bus routes in urban area, pp. 1796 - 1811

\begin{tabular}{|c|c|c|c|c|c|c|c|c|}
\hline \multirow{2}{*}{$\begin{array}{c}\text { Problem source } \\
\text { One transfer trips\% }\end{array}$} & \multicolumn{2}{|c|}{ Mandl [9] } & \multicolumn{2}{|c|}{$\begin{array}{c}\text { Baaj and } \\
\text { Mahmassani [10] }\end{array}$} & \multicolumn{2}{|c|}{$\begin{array}{c}\text { Shih and } \\
\text { Mahmassani [21] }\end{array}$} & \multicolumn{2}{|c|}{$\begin{array}{c}\text { Bagloee \&Ceder } \\
{[23]}\end{array}$} \\
\hline & 29.93 & 15.43 & 19.01 & 15.43 & 17.41 & 15.43 & 15.21 & 15.43 \\
\hline $\begin{array}{l}\text { Two transfer } \\
\text { trips } \%\end{array}$ & 0.13 & 0.16 & 0 & 0.16 & 0 & 0.16 & 0.95 & 0.16 \\
\hline $\begin{array}{l}\text { Route Network } \\
\text { Directness }\end{array}$ & 1.05 & 1.05 & 1.16 & 1.05 & 1.03 & 1.05 & $\mathrm{RNR}^{6}$ & 1.05 \\
\hline Transfer directness & 1.3 & 1.06 & 1.19 & 1.06 & 1.12 & 1.06 & RNR & 1.06 \\
\hline $\begin{array}{l}\text { Total route length } \\
\text { (min) }\end{array}$ & 82 & 110 & 106 & 110 & 151 & 110 & 261 & 110 \\
\hline $\begin{array}{l}\text { Total demand } \\
\text { served / TBF } \\
\text { (Trip/bus) }\end{array}$ & 157 & 157 & 190 & 190 & 186 & 186 & 179 & 179 \\
\hline $\begin{array}{l}\text { Average in-vehicle } \\
\text { time }\left(\mathrm{mpu}^{5}\right)\end{array}$ & 11.39 & 9.49 & 11.58 & 9.49 & 10.94 & 9.49 & 10.74 & 9.49 \\
\hline $\begin{array}{l}\text { Average waiting } \\
\text { time (mpu) }\end{array}$ & 1.17 & 1.25 & 1.46 & 1.51 & 1.29 & 1.55 & 1.58 & 1.44 \\
\hline $\begin{array}{l}\text { Total transfer } \\
\text { penalty (min) }\end{array}$ & 23500 & 9543 & 14800 & 9543 & 13550 & 9543 & 10465 & 9543 \\
\hline $\begin{array}{l}\text { Average transfer } \\
\text { Penalty (mpu) }\end{array}$ & 1.51 & 0.77 & 0.95 & 0.77 & 0.87 & 0.77 & 0.67 & 0.77 \\
\hline $\begin{array}{c}\text { Average total } \\
\text { travel time "ATT" } \\
(\mathrm{mpu})\end{array}$ & 14.07 & 11.51 & 13.99 & 11.77 & 13.1 & 11.81 & 12.99 & 11.7 \\
\hline $\begin{array}{l}\text { DRGA saving in } \\
\text { average user travel } \\
\text { time } \%\end{array}$ & \multicolumn{2}{|c|}{18.19} & \multicolumn{2}{|c|}{15.86} & \multicolumn{2}{|c|}{9.85} & \multicolumn{2}{|c|}{9.93} \\
\hline${ }^{1}$ Mandl's method & \multicolumn{4}{|c|}{${ }^{2}$ Baaj and Mahmassani's method } & \multicolumn{4}{|c|}{${ }^{3}$ Shih and Mahmassani's method } \\
\hline \multicolumn{5}{|c|}{-System $\quad 5$ minute per user } & \multicolumn{4}{|c|}{${ }^{6}$ Results not reported } \\
\hline
\end{tabular}

\section{Conclusions}

Transit Network Design Problem (TNDP) consists of two sub-problems; route design and frequency setting. The adopted approach aimed to solve the two problems in sequential manner. DRGA was proposed in a separate work paper to generate a set of efficient circular bus routes [13]. This paper concerns with frequency-based route choice models for passenger assignment. The interaction between transit user choice and given bus service pointed out that the problem is a mixed integer programming. GA as a powerful stochastic search tool has been implemented to solve the proposed model successfully. The proposed frequency setting model helps the designer to minimize total network travel time for a given bus fleet size by optimally distributing frequency among bus routes, while taking into account passengers' interests.

Results of comparison with pervious work have shown that DRGA and GA set of circular bus routes improved Mandl's transit network solution in terms of number of

Journal of Engineering Sciences, Assiut University, Faculty of Engineering, Vol. 41, No. 5, September, 2013,E-mail address: jes@aun.edu.eg 
constructed routes, transit service coverage, transfer directness, and solution mobility and reliability. Moreover, DRGA and GA circular bus routes manage in minimizing user cost (average user travel time) compared with other methods at the same operator cost.

It differs from literature models, since it helps in tracking different users while they are moving on the network. The results from this study would help in optimizing transit vehicle size and stops spacing along each single bus route.

In future work, elastic demand would be considered, in order to model the changes in the origin-destination matrix according to the supply of public transport. Further, more studies of TNDP with environmental impact would be considered in the future, since the impact of emissions on health and global warming is one of today's hot topics.

\section{Acknowledgment}

The author(s) would like to express their gratitude to Prof. Owais, M.A Prof. of transportation planning \& Traffic Eng., Civil Eng. Dept. Assuit Univ. (A.R.E), for his valuable advices and recommendations which contributed to this research work.

\section{Nomenclature}

\begin{tabular}{|c|c|}
\hline$A$ & the set of network arcs \\
\hline$A_{i}^{+}$ & the set of network arcs leaving node $\mathrm{i}$ \\
\hline$A_{i}^{-}$ & the set of network arcs entering node $\mathrm{i}$ \\
\hline$b_{i}$ & flow generated at $\mathrm{i}$ \\
\hline$D_{i}$ & total flow go through node $\mathrm{i}$ \\
\hline $\mathrm{D}_{\mathrm{o}}$ & total demand served without transfer \\
\hline $\mathrm{D}_{\mathrm{o} 1}$ & total demand served with one transfer \\
\hline $\mathrm{D}_{\mathrm{o} 2}$ & total demand served with two transfer \\
\hline$d_{i-j}$ & total transit trips from $(\mathrm{i})$ to $(\mathrm{j})$ \\
\hline $\begin{array}{l}\text { er } \\
f_{a}\end{array}$ & $\begin{array}{l}\text { second selected route to move from }(\mathrm{m}) \text { to }(\mathrm{k}) \text {, er } \in R_{m}^{k} \\
\text { frequency on arc a }\end{array}$ \\
\hline$f_{r}$ & frequency of route $(r)$ \\
\hline$f_{\min }$ & minimum bus frequency on route $r$ \\
\hline$f_{\max }$ & maximum bus frequency on route $r$ \\
\hline$g_{i-j}^{r}$ & number of trips from (i) to $(\mathrm{j})$ using $(\mathrm{r}), \mathrm{r} \in R_{i}^{j}$ \\
\hline $\mathrm{i}$ & represents the origin node, $\mathrm{i} \in N$ \\
\hline $\mathrm{j}$ & represents the destination node, $\mathrm{j} \in N$ \\
\hline $\mathrm{k}$ & set (i) destinated nodes satisfied with one transfer by $R_{i} ; \mathrm{k} \subset N$, \\
\hline 1 & set (i) destinated nodes satisfied without transfer by $R_{i} ; 1 \subset N$ \\
\hline $\mathrm{m}$ & Attractive transfer node for $(\mathrm{i}-\mathrm{j})$ trips, $\mathrm{j} \in k$ \\
\hline $\mathrm{N}$ & the set of network nodes \\
\hline $\mathrm{R}$ & set of bus routes $(r) ; r \in R$ \\
\hline$R_{i}$ & set of bus routes (r) pass through node (i) $R_{i} \subset R$ \\
\hline$R_{i}^{j}$ & set of bus routes (r) pass through nodes (i) and $(\mathrm{j}) ; R_{i}^{j} \subset R_{i}$ \\
\hline sr & first selected route to move from (i) to (m), sr $\in R_{i}^{m}$ \\
\hline TBF & total available bus fleet \\
\hline $\mathrm{T}_{\mathrm{r}}$ & bus route time length \\
\hline
\end{tabular}

Journal of Engineering Sciences, Assiut University, Faculty of Engineering, Vol. 41, No. 5, September, 2013,E-mail address: jes@aun.edu.eg 
$t_{i-j}^{r} \quad$ travel time between (i) and (j) through bus route (r)

$t_{a} \quad$ time on arc a

$v_{a} \quad$ flow on arc a

$\mathrm{V}_{\mathrm{s}} \quad$ Bus vehicle seating capacity (seats)

$\omega_{i} \quad$ total waiting time at node $\mathrm{i}$

$x_{a} \quad$ dummy variable, (1) if arc (a) belongs to attractive line set, (0) otherwise

$\delta_{i-j}^{r} \quad$ dummy variable (1)if it is attractive for (i-j) trips to use route (r), (0) otherwise

\section{References}

[1] Farahani, R. Z., Miandoabchi, E., Szeto, W.Y. and Rashidi, H., (2013), “A review of urban transportation network design problems", European Journal of Operational Research, Press.

[2] Chakroborty, P. 2003. Genetic algorithms for optimal urban transit network design. Computer - Aided Civil and Infrastructure Eng. Blackwell Publishing, Malden MA 02148, USA

[3] Ceder, A. and Wilson, N. 1986. Bus network design. Transportation Research Board Part B 20 (4), $331-344$.

[4] Zhao, F. and Gan, A. (2003) "Optimization of Transit Network to Minimize Transfers" Final Report, Research Office Florida Department of Transportation 605 Suwannee Street, MS Tallahassee FL 32399-0450.

[5] Pacheco, J. Alvarez, A. Casado, S. and Gonzalez-Velarde, JL 2009. A Tabu Search Approach to Urban Transport Problem in Northern Spain. Computers \& Operations

Research Vol. 36 Issue. 3 pp. 967-979.

[6] Wu, Y. and Szeto, W.Y., (2011)" A Simultaneous Bus Route Design and Frequency Setting Problem for Tin Shui Wai, Hong Kong" European Journal of Operational Research Vol. 209 No.2 pp. 141-155.

[7] Gao, Z, Sun, H. and Shan, L. (2004), “A Continuous Equilibrium Network Design Model and Algorithm for Transit Systems" Transportation Research Part B: Methodological, Volume 38, Issue 3, p. 235-250.

[8] Guan, J, Yang, H, and Wirasinghe, S, (2006), "Simultaneous Optimization of Transit Line Configuration and Passenger Line Assignment" Transportation Research Part B: Methodological, Volume 40, Issue 10, pp 885-902.

[9] Mandl, C.E. 1980. Evaluation and optimization of urban public transportation networks. European Journal of Operation Research 5(6), 396-404.

[10] Baaj, M. H. and Mahmassani, H. 1991. AI-based approach for transit route system planning and design. Journal of Advance Transportation 25(2), 187-210.

[11] Pattnaik, S. B., Mohan, S. and Tom,V. M. 1998. Urban Bus Transit Route Network Design Using Genetic Algorithm. Journal of Transportation Engineering - ASCE 124(4), 368-375.

[12] Mauttonw, A. and Urquhart, M. 2009. A route set construction algorithm for the transit network design problem. Computers and Operations Research 36 (8), 2440-2449.

[13] Owais, M. and Moussa, G. Abbas, Y. and El-Shabrawy, M. (2013), "Optimal Circular Bus Routes Planning for Transit Network Design Problem in Urban Areas”, Journal of Engineering Science, faculty of engineering, Assiut university, Vol. 41, issue (4).

[14] Desaulniers, G., and Hickman, M., (2007), "Handbook in OR \& MS" Elsevier, Vol. 14, Chapter 2. pp.69-83.

[15] Chriqui, C. and Robillard, P. (1975), “Common Bus Lines”, Hautes Eludes Commercials, Montréal, Québec, Canada, Transportation Science Vol. 9, No. 2, pp.115-121.

[16] Marguier, P. and Ceder, A. (1984), "Passenger Waiting Strategies for Overlapping Bus Routes", Massachusetts Institute of Technology, Cambridge, Massachusetts,

Journal of Engineering Sciences, Assiut University, Faculty of Engineering, Vol. 41, No. 5, September, 2013,E-mail address: jes@aun.edu.eg 
Transportation Science Vol. 18, No.3 pp. 207-230.

[17] Spiess, H. (1983), "On optimal route choice strategies in transit networks”, Publication 285, Centre de Recherche sur les Transports, Université de Montréal.

[18] Spiess, H., Florian,M. (1989),"Optimal strategies: A new assignment model for transit networks" Transportation Research - Part B 23 (2), 83-102.

[19] Goldberg, D. E. (1989), "Genetic Algorithm in Search, Optimization and Machine Learning", AddisonWesley, Reading, MA.

[20] Matlab 2011. Global Optimization Toolbox User's Guide, The Math Works, Inc.(1992), www.mathworks.com/help/pdf_doc/gads/gads_tb.pd

[21] Shih, M-C. and Mahmassani, H. 1994. A design methodology for bus transit networks with coordinated operation. SWUTC/94/60016-1, Center for Transportation,

Bureau of Engineering Research, the University of Texas at Austin, Austin, Texas.

[22] Zhao, F., 2006. Large-scale transit network optimization by minimizing transfers and user cost. Journal of Public Transportation 9 (2), 107-129.

[23] Bagloee, S. and Ceder, A. 2011. Transit-network design methodology for actual-size road networks. Transportation Research Part B 45(10), 1787-1804.

\section{التشغيل الامثل لخطوط نقل اتوبيسات دائرية فى المناطق الحضرية}

محمود محمد أحمد عويس, غادة موسى عبد الرحمن، يوسف على عباس، محمد الثبر اوى محمد

الملخص العربى

يهدف هذا البحث الى تخطيط وتنغيل شبكة نقل عام جيدة الاداء تغطى متطلبات حركة الركاب تنبع من

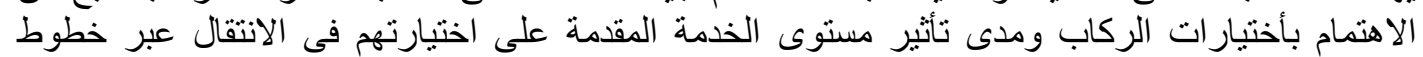

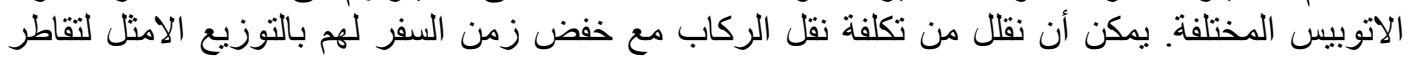

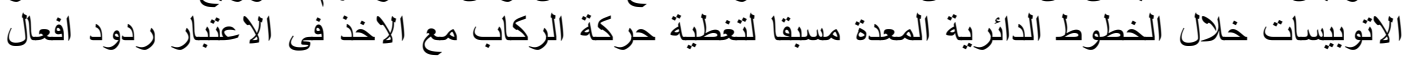

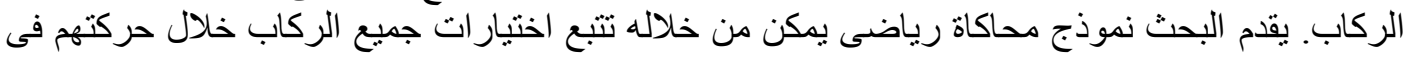

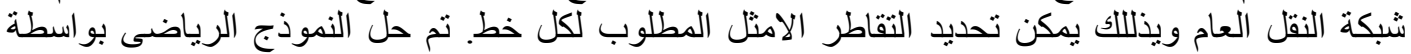

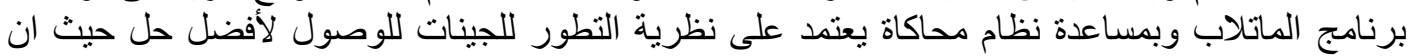

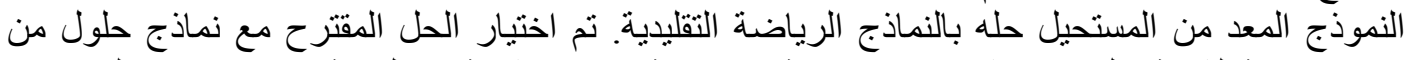

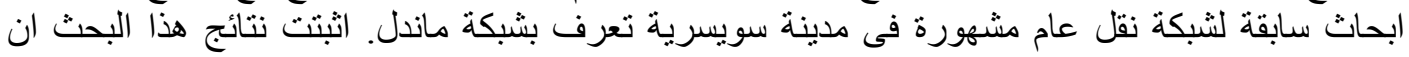

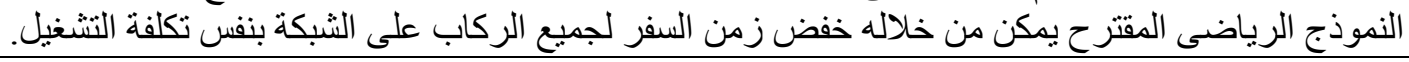
Journal of Engineering Sciences, Assiut University, Faculty of Engineering, Vol. 41, No. 5, September, 2013,E-mail address: jes@aun.edu.eg 